\title{
Towards a Second Generation of Ionic Liquid Matrices (ILMs) for MALDI-MS of Peptides, Proteins, and Carbohydrates
}

\author{
Jeffrey A. Crank and Daniel W. Armstrong \\ Chemistry and Biochemistry Department, University of Texas Arlington, Arlington, Texas, USA
}

Second generation ionic liquid matrices are developed, examined, and tested. They have shown a wide mass detection range $(<1000 \mathrm{Da}$ to $>270,000 \mathrm{Da})$ for proteins and peptides with greater $\mathrm{S} / \mathrm{N}$ ratios than solid matrices. These ionic liquid matrices also exhibit the ability to effectively ionize proteins of large mass without disrupting noncovalent interactions between monomers. Both the anionic and cationic moieties have been varied systematically to find an ionic liquid matrix with the best physical properties, analyte signal intensity, and widest mass detection range. It was determined that both the proton affinity and $\mathrm{pK}_{\mathrm{a}}$ of the cation have a large effect on the ionic liquid matrices' ability to effectively ionize the analyte. The ionic liquid matrices can be used to detect polysaccharides with fewer degradation products than solid matrices. $\mathrm{N}, \mathrm{N}$-diisopropylethylammonium $\alpha$-cyano-4-hydroxycinnamate and $\mathrm{N}$-isopropyl- $\mathrm{N}$ methyl-t-butylammonium $\alpha$-cyano-4-hydroxycinnamate were the best matrices for proteins and peptides, while $\mathrm{N}, \mathrm{N}$-diisopropylethylammonium $\alpha$-cyano-4-hydroxycinnamate and $\mathrm{N}, \mathrm{N}$ diisopropylethylammonium ferulate were the best matrices for carbohydrates. (J Am Soc Mass Spectrom 2009, 20, 1790-1800) (C) 2009 American Society for Mass Spectrometry

$\mathrm{T}$ There has been considerable interest in the properties and applications of ionic liquids (ILs). ILs are defined as nonmolecular salts that have a melting point below $100{ }^{\circ} \mathrm{C}$ and are called roomtemperature ILs if the melting point is at or below room temperature. There have been many applications of ILs, including solvents for organic synthesis and liquidliquid extraction [1-5], gas chromatography stationary phases [6-12] matrix assisted laser desorption/ionization (MALDI) matrices [13-19] and recently as ion pairing reagents for the trace analysis of anions by electrospray ionization mass spectrometry in the positive mode [20-22].

ILs used as MALDI matrices were first reported by Armstrong et al. in 2001 [14]. In this initial report, the authors showed the many advantages of using ILs as MALDI matrices, such as the homogeneity of the sample in the matrix, which leads to better shot to shot reproducibility, the negligible vapor pressure of the IL, and an increase in signal compared with solid matrices. It was also shown in a subsequent publication by $\mathrm{Li}$ and Gross [15] that the use of ionic liquid matrices (ILMs) enhanced quantitative analysis with MALDI compared with solid matrices. This improved quantification is mainly due to the homogeneity of the sample. Solid matrices such as $\alpha$-cyano-4-hydroxycinnamic acid (CHCA), ferulic acid (FA), and sinapinic acid (SA) rely on

Address reprint requests to Professor Daniel W. Armstrong, Chemistry and Biochemistry Department, University of Texas Arlington, Arlington TX 76019, USA. E-mail: Sec4DWA@uta.edu co-crystallization of matrix and analyte, which can lead to analyte/matrix heterogeneity and searching for so called "hot spots". These "hot spots" lead to poor shot to shot reproducibility. Other problems associated with solid matrices are difficult sample preparation, analyte size and/or type restrictions for different matrices [14], and harsh conditions used for preparation of the matrix [23]. Difficulty in sample preparation is typically caused by the analyte disrupting crystallization. Specific MALDI matrices are thought to be optimal for specific types and sizes (i.e., molecular weights) of analytes. For example, CHCA is typically used for proteins and peptides below $10,000 \mathrm{Da}$, whereas SA is typically used for proteins above $10,000 \mathrm{Da}$. The type of analyte is also important with regard to the matrix selected. Matrices that work well for one class of analytes may not work for another class even though they may be in the same molecular weight range. One example of this is the use of MALDI to detect carbohydrates and small proteins. CHCA is used for small proteins and 2,5-dihydroxybenzoic acid is used for carbohydrates. Harsh matrix preparation conditions can also be a problem with high molecular weight proteins that have noncovalently assembled subunits [23]. Typically, solid matrix preparation requires $0.05 \%-0.2 \%$ trifluoroacetic acid. This results in an acidic matrix solution which can disrupt these noncovalent interactions.

Ionic liquid matrices (ILMs) can be used to overcome many of the shortcomings of solid matrices. They are easily prepared, require no co-crystallization with the analyte, and produce homogeneous solutions of matrix 
and analyte, so there is no searching for "hot spots". ILMs also can be used for detection of many different types of analytes and for broader ranges of molecular sizes. Also ILMs use no trifluoroacetic acid in the sample preparation. Thus, a less acidic matrix is less likely to disrupt protein structural elements that require non-covalently assembled subunits.

Recent publications on ILMs show many applications for previously reported matrices [24-29], but very few new matrices have been synthesized. Also, to our knowledge, there have been no reports of exhaustive studies on how varying the IL's anionic and cationic moieties can affect the physical state of the ILM as well as the signal that can be achieved and/or the analyte specificity. In this study, we examine over 100 cation/ anion pairs and show that systematically changing the cation or anion will imbue the ILM with different desirable properties. Finally, we show how one ILM can be used for the detection of many analytes of a wide mass range $(<1000 \mathrm{Da}$ to $>270,000 \mathrm{Da})$, with stronger signals than can be obtained with solid matrices. In essence we develop, examine, and test the second generation of ionic liquid based MALDI matrices.

\section{Experimental}

\section{Materials and Instrument}

The following reagents were purchased from SigmaAldrich (St. Louis, MO, USA): $\alpha$-cyano-4-hydroxycinnamic acid, ferulic acid, sinapinic acid, diphenic acid, 2,5dihydroxybenzoic acid, all transretinoic acid, butylamine, octylamine, 2-aminopentane, triethanolamine, tributylamine, triisobutylamine, $\mathrm{N}, \mathrm{N}$-diisopropylethylamine, $\mathrm{N}$-isopropyl$\mathrm{N}$-methyl-tert-butylamine, (4-bromophenyl) diphenyl sulfonium bis(trifluoromethane)sulfonimide, 1,4-diaminobutane, triethylenetetramine hydrate, Nisopropyldiethylenetriamine, (4-methylthiophenyl) methyl phenyl sulfonium bis(trifluoromethane)sulfonimide, diphenyliodium bromide, naphthyl diphenylsulfonium bis(trifluoromethane)sulfonamide, anthraquinone-2carboxylic acid, bradykinin, polyethylene glycol 4600, insulin, cytochrome $c$, bovine serum albumin (BSA), catalase, urease, dextran enzymatic synthesis $\left(\mathrm{M}_{\mathrm{r}}=1500 \mathrm{Da}\right)$, and mannan from Saccharomyces cerevisiae. $\beta$-Cyclodextran was obtained from Advanced Separation Technologies Inc. (Whippany, NJ, USA). Solvents, microcetrifuge tubes and TFA were obtained from VWR (West Chester, PA, USA). All data were collected on a Bruker Autoflex mass spectrometer and analyzed with Bruker Flex Analysis Software. Carbohydrates were analyzed using Bruker PolyTools software (Billerica, MA, USA). All spectra shown are the sum of 100 laser shots with at least three spectra taken for each analyte to confirm analyte signal intensity consistency and mass. $\mathrm{pH}$ measurements were taken on an Orion 410A pH meter (Waltham, MA, USA).

\section{Matrix and Sample Preparation}

Stock solutions of analytes were prepared at the following concentrations: bradykinin $0.1 \mathrm{mM}$, dextran $0.1 \mathrm{mM}$, cyclodextrin $0.1 \mathrm{mM}$, cytochrome $c 0.1 \mathrm{mM}$, insulin $0.1 \mathrm{mM}$, polyethylene glycol $46000.1 \mathrm{mM}$, BSA $0.05 \mathrm{mM}$, catalase $0.05 \mathrm{mM}$, and urease $0.05 \mathrm{mM}$. Mannan was prepared as a $1 \mathrm{mg} / \mathrm{mL}$ solution because no molecular weight information could be obtained from the manufacturer.

Solid matrices were prepared according to the following procedure. A solution of water/acetonitrile (50/ 50 , vol/vol) with $0.1 \%$ TFA was added to microcentrifuge tubes containing the solid matrices SA, FA, and CHCA. The solutions were then vortexed to make saturated solutions of the matrices. The matrices were then mixed with the analyte in a ratio of 10:1 (matrix/ analyte, vol/vol) and vortexed to ensure complete mixing. Then, $1 \mu \mathrm{L}$ of the matrix/analyte solution was spotted on the MALDI plate and allowed to dry. 2,5-Dihydroxybenzoic acid (DHB) matrix solution was prepared by the following procedure. DHB was added to a solution of water/acetonitrile $(50 / 50, \mathrm{vol} / \mathrm{vol})$ with $0.1 \%$ TFA to make a $20 \mathrm{mg} / \mathrm{mL}$ solution. The DHB solution was then mixed with the analyte in a ratio from 10:1 (matrix/analyte, vol/vol) to 20:1 to find the optimal conditions for each analyte. The matrix/analyte solution was then vortexed to ensure complete mixing. Then, one $\mu \mathrm{L}$ of the matrix/analyte solution was spotted on the MALDI plate and allowed to dry. The apparent $\mathrm{pH}$ of the SA matrix solution was obtained by direct measurement of the hydro-organic solution with a $\mathrm{pH}$ meter.

ILMs were prepared as previously reported $[5,14]$. In short, one molar equivalent of solid matrix was dissolved in methanol. Then, one molar equivalent of base was added to the methanol solution, which was stirred for $30 \mathrm{~min}$ to ensure complete reaction. The solvent was then removed by rotary evaporator and the resulting ILM was placed under vacuum overnight to ensure dryness. NMR was used to confirm the ILMs structure. Next, the ILM was added to a microcentrifuge tube and ethanol was added to make a saturated solution. Note: most of the ILMs are either solids or glasses (supercooled liquids) when spotted on the MALDI plate. Lastly, the ILM solution was mixed with the analyte solution in a ratio of 10:1 (matrix/analyte $\mathrm{vol} / \mathrm{vol}$ ) and vortexed to ensure complete mixing. The mixture was then spotted on the MALDI plate and the ethanol was allowed to evaporate. For dicationic matrices, the same procedure was followed with the exception that two molar equivalents of base were added to the acid instead of one. Typically, methanol/matrix solutions are yellow, and when one equivalent of base is added, the solution changes to an orange color. When two equivalents of base are added, the solution turns red. Color change varies by matrix, with the most pronounced change seen with SA. This color change is due to the ionization of the carboxylic acid and then the phenolic group of the matrix. $\mathrm{pH}$ of the ILM matrix 
IMTBA CHCA was obtained by preparing a $0.1 \mathrm{M}$ solution of the matrix in water and measuring with a $\mathrm{pH}$ meter. The stability of dicationic ILMs under vacuum is similar to that of monocationic ILMs.

\section{Results and Discussion}

In this study, 114 matrices were tested and 105 new ionic liquids were prepared. Most of these ILMs show analyte signal for at least one or more analytes tested with a $\mathrm{S} / \mathrm{N}$ above 3 . Some ILMs produced much more intense signals with $\mathrm{S} / \mathrm{N}$ ratios greater than any of the solid matrices. All ILs used are listed in Table 1. Six of the 105 ILMs prepared showed increased analyte $\mathrm{S} / \mathrm{N}$ ratios compared with solid matrices. These ILMs are: $\mathrm{N}$-isopropyl-N-methyl-N-tert-butylammonium $\alpha$-cyano-4-hydroxycinnamate [IMTBA CHCA], N,Ndiisopropylethylammonium $\alpha$-cyano-4-hydroxycinnamate [DIEA CHCA], di(2-aminopentane) $\alpha$-cyano-4hydroxycinnamate [di(AP) CHCA], N-isopropyl-Nmethyl-N-tert-butylammonium ferulate [IMTBA FA], diisopropylethylammonium ferulate [DIEA FA], and di(2-aminopentane) ferulate [di(AP) FA]. In addition to producing higher $\mathrm{S} / \mathrm{N}$ ratios, use of these ILMs also resulted in an increased mass detection range compared with solid matrices.

Figure 1 shows a comparison of the IMTBA CHCA ionic liquid matrix with the solid matrices CHCA and SA over a wide mass range with the same laser power and analyte concentration. The laser power was decreased for spectra (d) and (k) because the intensity was too great for the ILM in spectra (c) and (j), resulting in poor resolution. Spectra (a)-(d) in Figure 1 show the detection of bradykinin (MW $=1060 \mathrm{Da})$ with the mass plus proton peak denoted as $[\mathrm{M}+\mathrm{H}]^{+}$. In these four spectra it can be seen that both the CHCA (Figure 1a) and IMTBA CHCA (Figure 1c) perform well. The resolution is poor in spectrum (a) and spectrum (c) due to high laser intensity, and is vastly improved to unit mass resolution with lower laser power, as can be seen in spectrum (d) (spectrum with reduced laser power for CHCA also achieves unit mass resolution with similar analyte signal intensity but is not shown).

Spectra (e)-(g) (Figure 1) show the detection of cytochrome $c(\mathrm{MW}=12,000 \mathrm{Da})$ with the same $[\mathrm{M}+$ $\mathrm{H}^{+}$notation. In this case, IMTBA CHCA far outperforms both CHCA and SA. Since CHCA is used for proteins $<10,000$ Da it did not detect cytochrome $c$ well. However, the addition of one equivalent of base to form IMTBA CHCA can increase the S/N for cytochrome $c$ by 19 times. The IMTBA CHCA matrix also produces a 2.6 times increase in S/N compared with the SA matrix.

Spectra (h)-(k) (see Figure 1) show the detection of BSA $(\mathrm{MW}=66,000 \mathrm{Da})$. Spectrum $(\mathrm{h})$ shows that CHCA can be used for high molecular weight analytes, but the mass resolution is typically poor. Also, many peaks are seen that cannot be identified and are assumed to be fragments of BSA. Spectrum (i) shows a clean spectrum obtained using the SA matrix. In this spectrum, peaks for $[\mathrm{M}+3 \mathrm{H}]^{3+},[\mathrm{M}+2 \mathrm{H}]^{2+},[2 \mathrm{M}+$ $3 \mathrm{H}]^{3+},[\mathrm{M}+\mathrm{H}]^{+},[4 \mathrm{M}+3 \mathrm{H}]^{3+},[3 \mathrm{M}+2 \mathrm{H}]^{2+},[2 \mathrm{M}+$ $\mathrm{H}]^{+}$, and $[3 \mathrm{M}+\mathrm{H}]^{+}$were observed and identified by mass [30-32]. Multiply charged peaks and singly charged peaks for $n$-mers of large proteins are expected and have been reported previously [30-32]. These reports show the detection of large proteins with solid matrices. However, in these reports different matrices and solvent systems for each protein are needed. Also, detecting large noncovalently assembled subunits can be problematic. ILMs use the same sample preparation for every protein tested and detect noncovalently assembled subunits easily. Spectrum (j) shows peaks for $[\mathrm{M}+\mathrm{H}]^{+},[\mathrm{M}+2 \mathrm{H}]^{2+},[2 \mathrm{M}+\mathrm{H}]^{+}$, and $[3 \mathrm{M}+\mathrm{H}]^{+} . \mathrm{A}$ $[4 \mathrm{M}+\mathrm{H}]^{+}$peak can also be seen in spectrum $(\mathrm{j})$, which is not seen when SA is used as a matrix. However, there are some peaks that are assumed to be fragments of the protein that could not be identified at this high laser intensity. Spectrum (k) shows the IMTBA CHCA ILM with a $6 \%$ laser power decrease. In this case the spectrum is much cleaner. Peaks that were identified in spectrum $(\mathrm{k})$ are $[\mathrm{M}+3 \mathrm{H}]^{3+},[\mathrm{M}+2 \mathrm{H}]^{2+},[\mathrm{M}+\mathrm{H}]^{+}$, $[3 \mathrm{M}+2 \mathrm{H}]^{2+},[2 \mathrm{M}+\mathrm{H}]^{+}$, and $[3 \mathrm{M}+\mathrm{H}]^{+}$. It should be noted that $n$-mers of BSA are artifacts of the MALDI process and are not observed in vivo.

Spectra (1)-(n) (see Figure 1) show the detection of urease, which is a hexamer in vivo with subunits that are 90,000 Da each. The CHCA (spectrum (1), Figure 1) does not show any peaks for urease. Spectrum (m) (using sinapinic acid) has two discernable peaks that are above a $\mathrm{S} / \mathrm{N}$ of 3 , corresponding to $[\mathrm{M}+\mathrm{H}]^{+}$and $[\mathrm{M}+2 \mathrm{H}]^{2+}$. The $[\mathrm{M}+3 \mathrm{H}]^{3+}$ peak can also be seen but the $\mathrm{S} / \mathrm{N}$ ratio is less than 2 . It is believed that the trifluoroacetic acid used in the sample preparation of the SA disrupts the noncovalent interactions between the urease subunits and, therefore, only the subunits are detected [32]. This can be explained by the fact that urease has an optimal activity $\mathrm{pH}$ of $\sim 7.2$ and will denature at low $\mathrm{pHs}(\sim 2)$ [33]. The SA/TFA solution has a $\mathrm{pH}$ of $\sim 2$ while the ionic liquid matrix has a $\mathrm{pH}$ of 7.8 (measured as outlined in the Experimental section). The low $\mathrm{pH}$ for the SA solution will affect the assembly of the monomers and most likely denature the protein $[30,33]$. Spectrum (n) shows that the ionic liquid matrix IMTBA CHCA far outperforms SA and CHCA with the $\mathrm{S} / \mathrm{N}$ of the $[\mathrm{M}+\mathrm{H}]^{+}$peak 1.7 times that of the $\mathrm{SA}[\mathrm{M}+\mathrm{H}]^{+}$peak. Other peaks that were identified include $[\mathrm{M}+3 \mathrm{H}]^{3+},[\mathrm{M}+2 \mathrm{H}]^{2+},[3 \mathrm{M}+2 \mathrm{H}]^{2+},[2 \mathrm{M}+$ $\mathrm{H}]^{+}$, and $\left[3 \mathrm{M}+\mathrm{H}^{+}\right.$. However, it is noted that the peaks for $[\mathrm{M}+3 \mathrm{H}]^{3+}$ and $[3 \mathrm{M}+2 \mathrm{H}]^{2+}$ have a $\mathrm{S} / \mathrm{N}$ ratio of $\sim 2$. $[4 \mathrm{M}+\mathrm{H}]^{+}$and $[5 \mathrm{M}+\mathrm{H}]^{+}$are not seen in this spectrum, and $[6 \mathrm{M}+\mathrm{H}]^{+}$is beyond the detection ability of the instrument. Similar results are seen in Figure 2 with the detection of catalase which is a tetramer in vivo with a monomer mass of 60,000 Da. Both CHCA and SA showed only a small monomer peak with $\mathrm{S} / \mathrm{N}$ ratios of 2 and 3 respectively. IMTBA $\mathrm{CHCA}$, on the other hand, shows $[\mathrm{M}+\mathrm{H}]^{+},[2 \mathrm{M}+$ $\mathrm{H}]^{+} /[4 \mathrm{M}+2 \mathrm{H}]^{2+},[5 \mathrm{M}+3 \mathrm{H}]^{2+},[3 \mathrm{M}+\mathrm{H}]^{+}$, and 
Table 1. ILs used as matrices for MALDI-TOF MS. In the second column the label "Solid" refers to Solids or Solids that are super cooled liquids. Analyte signal, yes, refers to the detection by the matrix of at least one analyte listed in the Experimental section with a $S / N \geq 3$

\begin{tabular}{|c|c|c|c|}
\hline Ionic liquid name & $\begin{array}{l}\text { Physical } \\
\text { state }\end{array}$ & $\begin{array}{l}\text { Previously } \\
\text { reported }[13,14,35]\end{array}$ & $\begin{array}{l}\text { Analyte } \\
\text { signal }\end{array}$ \\
\hline (4-Bromophenyl) diphenyl sulfonium NTF2 & Solid & & No \\
\hline (4-Methylthiophenyl) methyl phenyl sulfonium NTF2 & Liquid & & No \\
\hline Napthyl diphenylsulfonium NTF2 & Solid & & No \\
\hline (-)Cinchonidine NTF2 & Solid & & No \\
\hline Pyridinium 3-hydroxypicolinate & Solid & $\mathbf{X}$ & Yes \\
\hline $\mathrm{N}$-isopropyl-N-methyl-N-tert-butylammonium all-trans-retanoate & Solid & & No \\
\hline 1nonal-3-vinylimidazolium $\alpha$-cyano-4-hydroxycinnamate & Liquid & & Yes \\
\hline Methyl 1,3,5-triethylhexahydro-1,3,5-triazine triflate & Solid & & No \\
\hline Butylmethylimidizolium 3,4-dihydroxycinnamate & Liquid & & No \\
\hline Tributyl ammonium 3,4-dimethoxycinnamate & Liquid & & Yes \\
\hline Butylammonium 3,4-dihydroxycinnamate & Liquid & & Yes \\
\hline Octylammonium 3,4-dihydroxycinnamate & Glass & & Yes \\
\hline Decylammonium 3,4-dihydroxycinnamate & Solid & & Yes \\
\hline 1-(4-Hydroxypropyl)methylimidazolium iodate & Liquid & & No \\
\hline$\alpha$-Cyano-4-hydroxycinnamic acid & Solid & $\mathbf{x}$ & Yes \\
\hline 1-(4-Hydroxypropyl)methylimidazolium $\alpha$-cyano-4-hydroxycinnamate & Liquid & & Yes \\
\hline $\begin{array}{l}\text { 1-(2-Craboxyethyl)-3-(2-hydroxyethyl) imidazolium bromide 2(N-isopropyl- } \\
\mathrm{N} \text {-methyl-N-tert-butylamine) }\end{array}$ & Liquid & & No \\
\hline Butylmethylimidizolium $\alpha$-cyano-4-hydroxycinnamate & Liquid & $\mathbf{x}$ & Yes \\
\hline Dipenyliodonium $\alpha$-cyano-4-hydroxycinnamate & Solid & & No \\
\hline Tris-(2-hydroxyethyl)-sulfonium $\alpha$-cyano-4-hydroxycinnamate & Solid & & Yes \\
\hline Tributylammonium $\alpha$-cyano-4-hydroxycinnamate & wax & & Yes \\
\hline$d i($ Tributylammonium) $\alpha$-cyano-4-hydroxycinnamate (not formed) & NA & & Yes \\
\hline Diisopropylethylammonium $\alpha$-cyano-4-hydroxycinnamate & Glass & & Yes \\
\hline$d i($ Diisopropylethylammonium) $\alpha$-cyano-4-hydroxycinnamate (not formed) & NA & & Yes \\
\hline $\mathrm{N}$-isopropyl-N-methyl-N-tert-butylammonium $\alpha$-cyano-4-hydroxycinnamate & Glass & & Yes \\
\hline $\begin{array}{l}d i(\mathrm{~N} \text {-isopropyl-N-methyl-N-tert-butylammonium) } \alpha \text {-cyano-4-hydroxycinnamate } \\
\text { (not formed) }\end{array}$ & NA & & Yes \\
\hline Butylammonium $\alpha$-cyano-4-hydroxycinnamate & Solid & $\mathbf{X}$ & Yes \\
\hline$d i($ Butylammonium) $\alpha$-cyano-4-hydroxycinnamate & Glass & & Yes \\
\hline Octylammonium $\alpha$-cyano-4-hydroxycinnamate & Solid & & Yes \\
\hline di(Octylammonium) $\alpha$-cyano-4-hydroxycinnamate & Glass & & Yes \\
\hline Decylammonium $\alpha$-cyano-4-hydroxycinnamate & Solid & & Yes \\
\hline 2-Amino pentane $\alpha$-cyano-4-hydroxycinnamate & Solid & & Yes \\
\hline$d i(2$-Aminopentane) $\alpha$-cyano-4-hydroxycinnamate & Solid & & Yes \\
\hline di $(1,1,3,3-$ Tetramethyl-guanidinium) $\alpha$-cyano-4-hydroxycinnamate & Solid & $\mathbf{X}$ & Yes \\
\hline Ferulic acid & Solid & $\mathbf{X}$ & Yes \\
\hline Butylammonium ferulate & Glass & & Yes \\
\hline$d i($ Butylammonium) ferulate & Solid & & Yes \\
\hline Octylammonium ferulate & Solid & & Yes \\
\hline di(Octylammonium) ferulate & Solid & & No \\
\hline Decylammonium ferulate & Solid & & Yes \\
\hline Tributylammonium ferulate & Solid & & Yes \\
\hline di(Tributylammonium) ferulate (not formed) & NA & & Yes \\
\hline Diisopropylethylammonium ferulate & Solid & & Yes \\
\hline$d i($ Diisopropylethylammonium) ferulate (not formed) & Solid & & Yes \\
\hline Diisopropylethylammonium triethanolammonium ferulate (not formed) & NA & & No \\
\hline (N-isopropyl-N-methyl-N-tert-butylammonium) ferulate & Solid & & Yes \\
\hline$d i(\mathrm{~N}$-isopropyl-N-methyl-N-tert-butylammonium) ferulate (not formed) & NA & & Yes \\
\hline $\begin{array}{l}\mathrm{N} \text {-isopropyl-N-methyl-N-tert-butylammonium diisopropylethylammonium } \\
\text { ferulate (not formed) }\end{array}$ & NA & & Yes \\
\hline 2-Aminopentane ferulate & Solid & & Yes \\
\hline$d i(2-A m i n o p e n t a n e)$ ferulate & Solid & & Yes \\
\hline 2-Amino-2-phenylethanol ferulate & Solid & & No \\
\hline 1,4-Diaminobutane di(ferulate) & Solid & & Yes \\
\hline Diethylenetriammonium tri(ferulate) & Solid & & Yes \\
\hline Triisobutylammonium tri(ferulate) & Solid & & Yes \\
\hline Diethylenetriammonium di(ferulate) ( $\alpha$-Cyano-4-hydroxycinnamate) & Solid & & Yes \\
\hline Diethylenetriamine ferulate $\alpha$-Cyano-4-hydroxycinnamate sinapinate & Solid & & Yes \\
\hline $\mathrm{N}$-isopropyldiethylenetriammonium tri(ferulate) & Solid & & No \\
\hline Triethylenetetraammonium (ferulate) $_{4}$ & Solid & & Yes \\
\hline
\end{tabular}


Table 1. Continued

\begin{tabular}{|c|c|c|c|}
\hline Ionic liquid name & $\begin{array}{l}\text { Physical } \\
\text { state }\end{array}$ & $\begin{array}{c}\text { Previously reported } \\
{[13,14,35]}\end{array}$ & $\begin{array}{c}\text { Analyte } \\
\text { signal }\end{array}$ \\
\hline$d i($ Triethanolammonium) ferulate (not formed) & NA & & No \\
\hline Triethanolammonium ferulate & Liquid & & No \\
\hline Diisopropylethylammonium anthraquinone-2-carboxylate & Solid & & Yes \\
\hline Sinapinic acid & Solid & $\mathbf{X}$ & Yes \\
\hline Tributylammonium Sinapinate & Liquid & $\mathbf{X}$ & Yes \\
\hline Butylammonium sinapinate & Solid & & Yes \\
\hline di(Butylammonium) sinapinate & Solid & & Yes \\
\hline Octylammonium sinapinate & Solid & & Yes \\
\hline di(Octylammonium) sinapinate & Solid & & Yes \\
\hline Tributylammonium sinapinate & Wax & $\mathbf{x}$ & Yes \\
\hline$d i($ Tributylammonium) sinapinate(not formed) & NA & & NA \\
\hline Diisopropylethylammonium sinapinate & Solid & & Yes \\
\hline di(Diisopropylethylammonium) sinapinate (not formed) & NA & & Yes \\
\hline (N-isopropyl-N-methyl-N-tert-butylammonium) sinapinate & Solid & & Yes \\
\hline $\operatorname{di}(\mathrm{N}$-isopropyl-N-methyl-N-tert-butylammonium) sinapinate (not formed) & NA & & Yes \\
\hline 2-Aminopentane sinapinate & Solid & & Yes \\
\hline di(2-Aminopentane) sinapinate & Solid & & Yes \\
\hline 7-Hydroxycoumarinyl-4-acetic acid & Solid & & Yes \\
\hline Diisopropylethylammonium 7-hydroxycoumarinyl-4-acetate & Solid & & No \\
\hline $\mathrm{N}$-isopropyl-N-methyl-N-tert-butylammonium 7-hydroxycoumarinyl-4-acetate & Solid & & No \\
\hline Aurintricarboxylic acid & Solid & & No \\
\hline Diisopropylethylammonium aurintricarboxylate & Solid & & No \\
\hline $\mathrm{N}$-isopropyl-N-methyl-N-tert-butylammonium aurintricarboxylate & Solid & & No \\
\hline 2,3-Benzofurandicarboxylic acid & Solid & & No \\
\hline Diisopropylethylammonium 2,3-benzofurandicarboxylate & Solid & & No \\
\hline $\mathrm{N}$-isopropyl-N-methyl-N-tert-butylammonium 2,3-benzofurandicarboxylate & Solid & & No \\
\hline 3,6-Dihydroxyflavone & Solid & & No \\
\hline Diisopropylethylammonium 3,6-dihydroxyflavone & Solid & & No \\
\hline $\mathrm{N}$-isopropyl-N-methyl-N-tert-butylammonium 3,6-dihydroxyflavone & Solid & & No \\
\hline 9-Hydroxy-9-fluorenecarboxylic acid & Solid & & No \\
\hline Diisopropylethylammonium 9-hydroxy-9-fluorenecarboxylate & Solid & & No \\
\hline $\mathrm{N}$-isopropyl-N-methyl-N-tert-butylammonium 9-hydroxy-9-fluorenecarboxylate & Solid & & No \\
\hline 2-(4-Hydroxyphenylazo)benzoic acid & Solid & & Yes \\
\hline Diisopropylethylammonium 2-(4-hydroxyphenylazo)benzoate & Solid & & Yes \\
\hline $\mathrm{N}$-isopropyl-N-methyl-N-tert-butylammonium 2-(4-hydroxyphenylazo)benzoate & Solid & & Yes \\
\hline Mellitic acid & Solid & & No \\
\hline Diisopropylethylammonium mellitate & Solid & & No \\
\hline $\mathrm{N}$-isopropyl-N-methyl-N-tert-butylammonium mellitate & Solid & & No \\
\hline 2,3-Naphthalenendicarboxylic acid & Solid & & No \\
\hline Diisopropylethylammonium 2,3-naphthalenendicarboxylate & Solid & & No \\
\hline $\mathrm{N}$-isopropyl-N-methyl-N-tert-butylammonium 2,3-naphthalenendicarboxylate & Solid & & No \\
\hline Diisopropylethylammonium curcumin & Solid & & No \\
\hline Piperidinium $\alpha$-cyano-4-hydroxycinnamate & Glass & & Yes \\
\hline $2,2,6,6$-Tetramehtylpiperidine $\alpha$-cyano-4-hydroxycinnamate & Solid & & Yes \\
\hline 2,2,6,6-Tetramethyl-4-piperidone $\alpha$-cyano-4-hydroxycinnamate & Solid & & Yes \\
\hline $2,2,6,6$-Tetramehtylpiperidinol $\alpha$-cyano-4-hydroxycinnamate & Solid & & Yes \\
\hline 2,2,5,5-Tetramethyl-3-pyrroline-3-carboxamide $\alpha$-cyano-4-hydroxycinnamate & Solid & & Yes \\
\hline Hexamethyldisilazane $\alpha$-cyano-4-hydroxycinnamate & Solid & & No \\
\hline Quinuclidinium $\alpha$-cyano-4-hydroxycinnamate & Solid & & Yes \\
\hline Dicyclohexylammonium $\alpha$-cyano-4-hydroxycinnamate & Solid & & Yes \\
\hline 2,5-Dihydroxybenzoic acid & Solid & $\mathbf{X}$ & Yes \\
\hline $\mathrm{N}$-isopropyl-N-methyl-N-tert-butylammonium 2,5-Dihydroxybenzoate & Solid & & Yes \\
\hline Diisopropylethylammonium 2,5-dihydroxybenzoate & Solid & & Yes \\
\hline Rutin & Solid & & Yes \\
\hline Diisopropylethylammonium rutin & Solid & & Yes \\
\hline
\end{tabular}

$[4 \mathrm{M}+\mathrm{H}]^{+}$peaks, with all peak intensities greater than or equal to a $\mathrm{S} / \mathrm{N}$ ratio of 3 (Figure 2). Currently it is not known if the $n$-mers are the original complexes or artifacts of the MALDI process. Further study is needed to discern the true origin of the complexes. Other analytes of interest that were tested are polyethylene glycol 4600, insulin (MW $=5700 \mathrm{Da})$, and $\beta$-Cyclodextran $(\mathrm{MW}=1135 \mathrm{Da})$. These analytes were detected using ILMs, and show higher signal intensities than solid matrices (data not shown). 


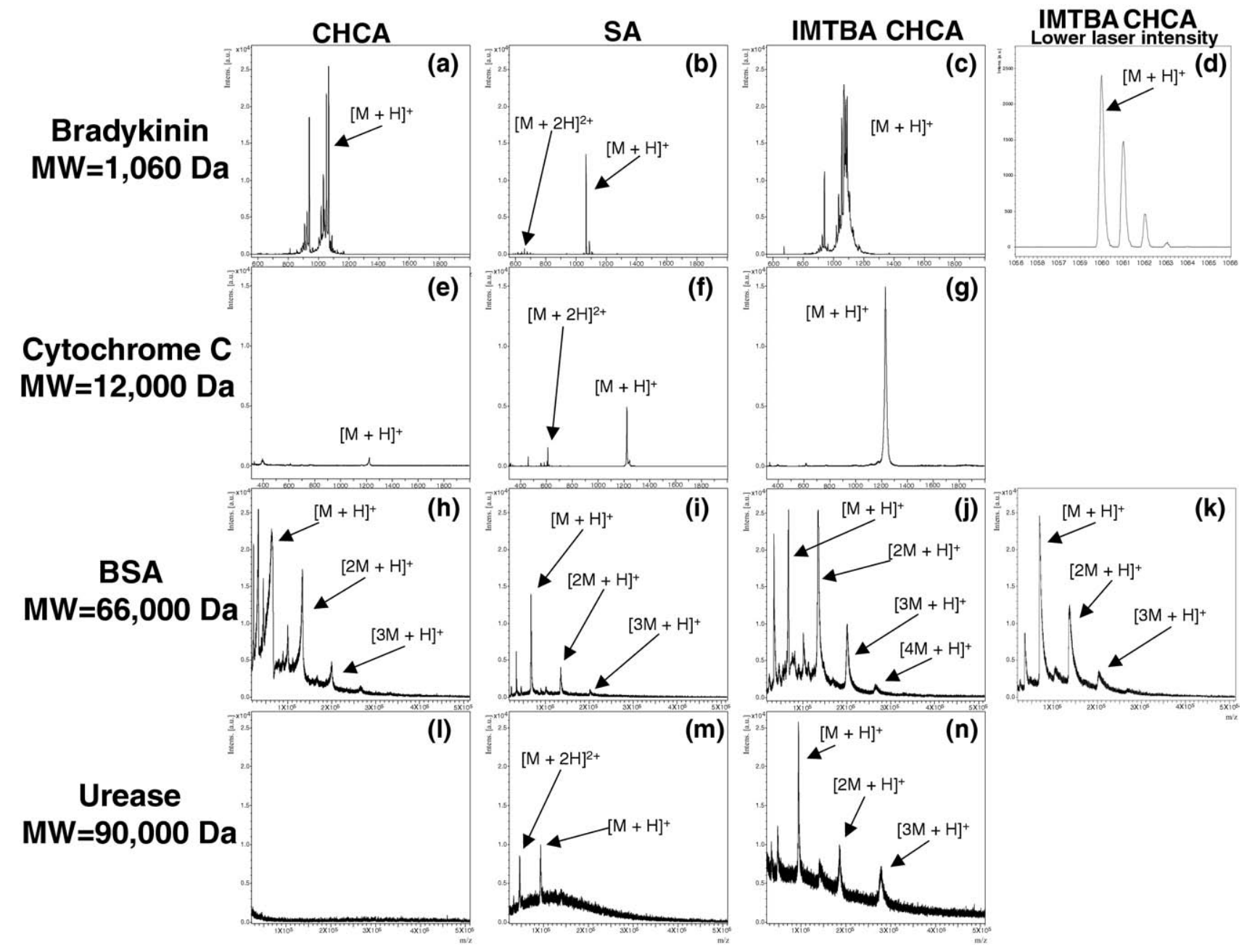

Figure 1. Comparison of solid matrices and an ILM (columns) with four different analytes (rows). CHCA, SA, and IMTBA CHCA are compared using the same laser power and analyte concentration. Analytes shown are bradykinin $(\mathrm{MW}=1060 \mathrm{Da})$, cytochrome $c(\mathrm{MW}=12,000 \mathrm{Da}), \mathrm{BSA}(\mathrm{MW}=66,000$ $\mathrm{Da})$, and urease (monomer MW $=90,000 \mathrm{Da})$. Peaks are labeled in the $[\mathrm{M}+\mathrm{H}]^{+}$notation. Spectra $(\mathrm{d})$ and (k) show bradykinin and BSA, respectively, at lower laser powers to show that good resolution is achieved. Spectrum (n) shows a $[3 \mathrm{M}+\mathrm{H}]^{+}$peak with a mass of 270,000 Da.

\section{Physical Properties of ILMs}

The physical states of these ILMs vary between that of solids, waxes, glasses, or liquids. Most of the ILMs synthesized exist as supercooled liquids when spotted on the MALDI plate. It was observed that the ferulate ILMs are more likely to be super-cooled liquids than CHCA or sinapinate based ILs.

The effect of the cation on the ILM physical state was studied by varying the alkyl chain length, symmetry, and size of the amines. Butylamine, octylamine, and decylamine were paired with CHCA, FA, and SA to see if there is an effect of carbon chain length on physical state. It was found that there is a little or no difference in the physical state of the ILM when changing carbon chain length from 4 to 10 carbons. Unsymmetrical amines such as N-isopropyl-N-methyl-N-tert-butylamine and $\mathrm{N}, \mathrm{N}$ diisopropylethylamine were used as ILM cations to determine if the lack of symmetry would decrease the melt- ing point of the ILM. It was found that the unsymmetric cations only decreased the melting points of the ILMs by $1-2{ }^{\circ} \mathrm{C}$. However, unsymmetric sterically hindered amines did produce an increase in analyte signal as will be discussed below. One tertiary amine that did lower the melting point of ILMs was triethanolamine. Pairing of triethanolamine with any solid matrix resulted in a room-temperature ILM. However, no triethanolamine (TEA) ILM showed any analyte signal. This phenomenon is discussed in the cation effect on signal intensity section. ILMs with two different cations were also synthesized in an attempt to lower melting temperatures. Mixed cation ILMs showed a slight decrease $\left(1-2{ }^{\circ} \mathrm{C}\right)$ in melting temperature but did not show any major advantages over ILMs with two identical cations. Also, it is interesting to note that if TEA is added as a second cation to any ILM that works well, subsequently no analyte signal can be detected. 


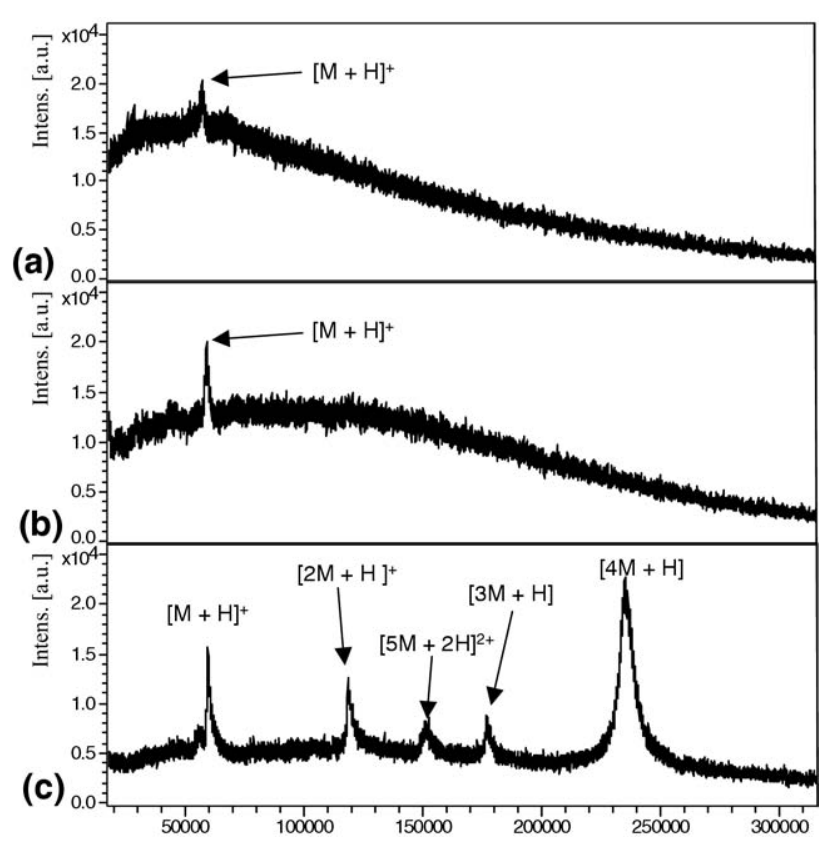

Figure 2. Detection of catalase (monomer $\mathrm{MW}=60,000 \mathrm{Da}$ ) with: (a) CHCA, (b) SA, and (c) IMTBA CHCA. Peaks are labeled with $[\mathrm{M}+\mathrm{H}]^{+}$notation. The tetramer peak $(\mathrm{MW}=240,0000 \mathrm{Da})$ is labeled $[4 \mathrm{M}+\mathrm{H}]^{+}$.

\section{Anion Effects on Signal Intensity}

Previously it was assumed that the effect of the ILM anion on analyte signal and detection might be somewhat analogous to that observed for solid matrices [14], which is that a CHCA ILM should be better for small analytes $(<10,000 \mathrm{Da})$, and a sinapinate ILM should be preferable for large analytes $(>10,000 \mathrm{Da})$. However, Figure 3 shows BSA $(66,000 \mathrm{Da})$ has higher signal intensity using a CHCA-ILM than with a SA-ILM. The molecular weight limitations of solid MALDI matrices do not apply to the ionic liquid matrices. This will be discussed subsequently. Also, Figure 3 shows how the intensity of the BSA signal changes with the ILM: IMTBA CHCA (a), IMTBA ferulate (b), and IMTBA sinapinate (c). The $\mathrm{S} / \mathrm{N}$ for the $[\mathrm{M}+\mathrm{H}]^{+}$peak of IMTBA CHCA is 7.1 times greater than IMTBA sinapinate, 1.6 times greater than IMTBA ferulate. As a general trend for ILM anions with protein analytes, the signal decreases in going from $\alpha$-cyano-4hydroxycinnamate to ferulate to sinapinate. To elucidate why $\alpha$-cyano-4-hydroxycinnamate produces greater signal than ferulate and sinapinate, the proton affinities and pKa of the acids were examined. The proton affinities and the $\mathrm{pK}_{\mathrm{a}}$ of the acids CHCA, ferulic acid, and sinapinic acid have been published previously [34-37]. However, in this work there seems to be no correlation between these properties and the analyte signal produced.

In this study, many ILMs have been made with new anions, but as of yet none have surpassed the signal intensity achieved by IL analogues of CHCA, ferulic acid, and sinapinic acid. Unique anions, such as anthroquinone-2-carboxylate, all trans-retinoate, and 1-(2-carboxyethyl)-3-(2-hydroxyethyl) imidazolium bromide have been used to make ILMs, with each having its own unique drawbacks. Anthroquinone-2-carboxylic acid was paired with DIEA and became a supercooled ILM. However, signals achieved with the anthroquinone were low, and many extraneous peaks were observed. The retinoic acid ILM is extremely hydrophobic and solubility issues with the analytes and this ILM were observed. 1-(2-Carboxyethyl)-3-(2-hydroxyethyl) imidazolium bromide was paired with IMTBA, which formed a room-temperature IL. However, this ILM did not give sufficient signal for any analyte tested. The search for new anions is ongoing.

\section{Cation Effects on Signal Intensity}

The cation of ILMs has a large effect on signal intensity and physical state (solid, liquid, glass) and has been studied systematically. Typical cations used in previous studies are ethylamine, butylamine, tributylamine, and various pyridine derivatives $[5,14]$. These cations were chosen at random from a pool of amines. In this study, both chain length and the steric bulk were varied to find optimal cations. Butylamine, octylamine, and decylamine were used to see the effect of carbon chain length on signal intensity. The intensity of the analyte peaks corresponding to these ILMs can vary drastically. Typically, the signal intensity resulting from the butylamine ILs are the most intense, followed by octylamine and decylamine, although the protein peaks are still not as intense as with solid ferulic acid (see Supplemental Information Figure SI 1, decylammonium ferulate not shown, which can be found in the electronic version of this article).

The effect of steric bulk of the cation on signal intensity was studied systematically. This was done by

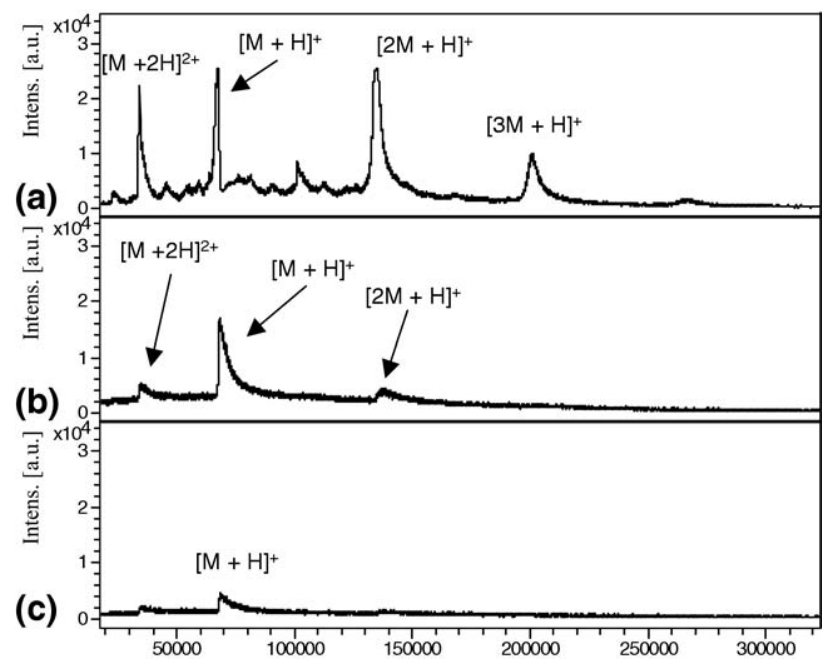

Figure 3. Effect of the anion on signal intensity with the matrices (a) IMTBA CHCA, (b) IMTBA ferulate, and (c) IMTBA sinapinate at the same laser power and analyte (BSA) concentration. Peaks are labeled with $[\mathrm{M}+\mathrm{H}]^{+}$notation. 
pairing a variety of substituted amines with CHCA, FA, and SA to produce ILMs. The amines tested were butylamine (BA), 2-aminopentane (AP), tributylamine (TBA), N,N-diisopropylethylamine (DIEA), N-isopropylN-methyl-tert-butylamine (IMTBA), and triisobutylamine (TIBA) giving a wide range of sterically bulky amines. Figure SI shows that matrices containing sterically hindered amines produce much higher analyte signal intensities than primary amines for all analytes tested. However, steric factors alone are not the only factor that contributes to the analyte signal intensity. This can be seen in the case of the AP and TBA cations. $\mathrm{AP}$ is a primary amine that often gives an analyte signal intensity that is equal to or greater than TBA. TBA is a tertiary amine that does not give signal intensities that are expected for a sterically hindered amine. TBA often shows little or no analyte signal. It is not structurally evident why TBA produces poor analyte signal intensities. Apparently, possible explanations for a cation's effectiveness as a matrix component involve its $\mathrm{pK}_{\mathrm{a}}$ and proton affinity (PA). Essentially, the $\mathrm{pK}_{\mathrm{a}}$ represents the solution phase acidity of the protonated amine and the PA represents the acidity in the gas phase of the conjugate base of the amine. When considering ILM cations that work well, a general trend is observed. Cations must have a high $\mathrm{pK}_{\mathrm{a}}(\geq 11)$ and PA $(>930$ $\mathrm{kJ} / \mathrm{mol}$ ) as seen in Table 2. If either the PA or $\mathrm{pK}_{\mathrm{a}}$ is low, the matrix tends to perform poorly. TBA has a $\mathrm{pK}_{\mathrm{a}}$ of 9.9 and a PA of $998.5 \mathrm{~kJ} / \mathrm{mol}$ [38]. In comparison, other tertiary amines that work well as ILM cations, such as DIEA, has a $\mathrm{pK}_{\mathrm{a}}$ of 11.4 and a PA of $994.3 \mathrm{~kJ} / \mathrm{mol}$ [38]. TBA's $\mathrm{pK}_{\mathrm{a}}$ is only slightly above that of ammonia (9.24). Other cations that do not work well as ILM cations have similar or lower $\mathrm{pK}_{\mathrm{a}} \mathrm{s}$. One of these cations is TIBA with a proton affinity of $967.6 \mathrm{~kJ} / \mathrm{mol}$ [38] and a $\mathrm{pK}_{\mathrm{a}}$ of 9.51 . TIBA is so sterically hindered that the proton transfer does not happen easily in solution with the matrix acids CHCA, FA, and SA. Typically, when synthesizing TIBA ILMs, after removal of the solvent, neat TIBA will collect in the bottom of the flask after 2-3 min.

Other cations of interest that did not produce good results are triethanol amine (TEA), 1,4-diaminobutane, triethylenetetramine hydrate, and $\mathrm{N}$-isopropyldiethylenetriamine. It was originally thought that TEA would help with the ionization process and lower the melting point of the
ILMs. All TEA ILMs were room-temperature ILs, however, no analyte signal was observed with any TEA based matrix. This phenomenon can also be explained by the $\mathrm{pK}_{\mathrm{a}}$ and proton affinity. TEA has a $\mathrm{pK}_{\mathrm{a}}$ of 7.8 and $\mathrm{a}$ proton affinity of $941 \mathrm{~kJ} / \mathrm{mol}$ [39]. TEA has a moderate proton affinity but a relatively acidic $\mathrm{pK}_{\mathrm{a}}$ compared with other protonated amines. It was also hypothesized that 1,4-diaminobutane, triethylenetetramine, and Nisopropyldiethylenetriamine might be good cations for ILMs because multiple anions can be paired with single molecules of di-, tri-, or tetra-amines. However, there was no increase in signal for the analytes tested compared with other ILMs, and the melting point was not decreased enough to make a room-temperature ILM. Also, in an attempt to lower melting point and increase the analyte signal intensity for low and high molecular weight analytes, different anions were paired with a di-, tri-, or tetra-amine molecules. SA, FA, and CHCA were paired with a triamine but did not show improved signal or a lower melting point. Two FA molecules and one CHCA molecule were also paired with a triamine with similar unimpressive results. $\mathrm{Di}(1,1,3,3$-tetramethyl-guanidinium) $\alpha$-cyano4-hydroxycinnamate [29] was also evaluated. Di(1,1,3,3tetramethyl-guanidinium) $\alpha$-cyano-4-hydroxycinnamate has shown satisfactory results with bradykinin but failed to produce adequate signal for cytochrome $c$ and mannan.

The effect of using multiple cations also was explored. All acids tested (SA, FA, and CHCA) have two ionizable groups (one phenolic $\mathrm{OH}$ and one carboxylic $\mathrm{OH})$. Systematic testing of the matrices with zero (solid matrices), one, and two cations was performed. It was found that the addition of one or two cations may increase the signal intensity, but the benefits of adding cations to solid matrices must be evaluated on a case by case basis. The effects of multiple cations can be seen in Figure SI 3 for the detection of cytochrome $c$ with CHCA (A), BA CHCA (B), and di(BA) CHCA (C). The addition of one and two cations increases the analyte signal. The signal is increased by a factor of 2 when one butylamine is added and by a factor of 4 when two butylamines are added. The presence of 2 BA molecules was verified by NMR by the disappearance of the acidic

Table 2. ILM ammonium properties arranged by increasing $\mathrm{pK}_{\mathrm{a}}$. In the proton affinity (PA) and gas phase basicity (GB) columns NA represents not available. In the performance versus Solid matrix column " $X$ " represents ILM cations that did not pair well with the Solid matrices or showed no analyte signal, "-" represents ILM cations that show signal but less than the Solid matrix, "+" represents ILM cations that performed as well or marginally better than the Solids, and "++" represents ILMs that outperform the Solid matrices

\begin{tabular}{lcccc}
\hline \multicolumn{1}{c}{ Amine name } & $\mathrm{pK}_{\mathrm{a}}$ & $\mathrm{PA}(\mathrm{kJ} / \mathrm{mol})$ & $\mathrm{GB}(\mathrm{kJ} / \mathrm{mol})$ & Performance versus Solid matrix \\
\hline \hline Triethanolamine & 7.8 & 941 & $\mathrm{NA}$ & $\mathbf{X}$ \\
Triisobutylamine & 9.5 & 967.6 & 998.5 & $\mathbf{X}$ \\
Tributylamine & 9.9 & 998.5 & 967.6 & - \\
Butylamine & 10.6 & 921.5 & 886.6 & - \\
2-Amino butane & 10.7 & 929.9 & 895.7 & + \\
$N$-isopropyl- $N$-methyl-t-butylamine & 10.9 & $\mathrm{NA}$ & $\mathrm{NA}$ & ++ \\
N,N-diisopropylethylamine & 11.4 & 994.3 & 963.5 & ++ \\
\hline
\end{tabular}


protons and the integration of the spectrum (see Supplemental Information, SI 2).

However, addition of multiple equivalents of base does not necessarily guarantee the removal of the phenolic proton and an increase in signal. Figure $\mathrm{S} 3$ shows the detection of cytochrome $c$ with CHCA (A), IMTBA CHCA (B), and di(IMTBA) CHCA (C). When one cation is added the $\mathrm{S} / \mathrm{N}$ increases by a factor of 24 , and when the second IMTBA is added, there does not appear to be further improvement in the $\mathrm{S} / \mathrm{N}$. This phenomenon can be explained by the NMR spectrum of di(IMTBA) CHCA. Through NMR it is seen that the sterically hindered bases (DIEA and IMTBA) do not remove the phenolic proton, and only one equivalent of base is present. No further improvement in analyte signal intensity is seen because the second equivalent of base is removed when placed under vacuum (see Experimental section and Supplemental Information, SI 4).

\section{Detection of Polysaccharides}

Detection and molecular weight determination of polysaccharides is important for the characterization of natural polymers, such as dextrans and mannans. Size exclusion chromatography (SEC) will give a mass range, but can sometimes over- or underestimate the molecular weight because the standards used are not structurally or chemically similar to the polymer being analyzed [40, 41].

MALDI-MS of these polymers displays its own unique drawbacks. Acid content of the matrix or the solution used to integrate the sample and matrix will start to degrade the polymer. Thus, some structural information can be obtained, but any useful information about the average molecular weight of the polymer is obscured. Also, co-crystallization with the matrix is problematic since these polymers typically form viscous solutions when dissolved. When the concentration of polymer is decreased, satisfactory crystallization was achieved.

ILMs are ideally suited to overcome each of the aforementioned drawbacks because no acid is added and no crystallization is needed. Figure 4 shows the detection of Dextran 1500 with (a) DHB, (b) DIEA FA, and (c) DIEA CHCA. DHB ILM analogs were also tested but produced spectra similar to the DHB matrix spectrum (data not shown). Figure 4a shows that adequate signal is observed with DHB. Peaks in Figure 4a differ by 162 Da corresponding to the mass differences of the glucose units. The identified peak distribution has a mass range from 365 to $2311 \mathrm{Da}$, which corresponds to two to 14 sodiated glucose units. Apparently the acid content of the DHB partially degraded the sample, resulting in a distribution of $\mathrm{m} / \mathrm{z}$ that almost exponentially increases toward the low mass region of the spectrum. The number average molecular weight $\left(\mathrm{M}_{\mathrm{n}}\right)$ and weight average molecular weight $\left(\mathrm{M}_{\mathrm{w}}\right)$ obtained (see the Experimental section) for dextran 1500 with the DHB matrix are 727 and $787 \mathrm{Da}$, respectively.

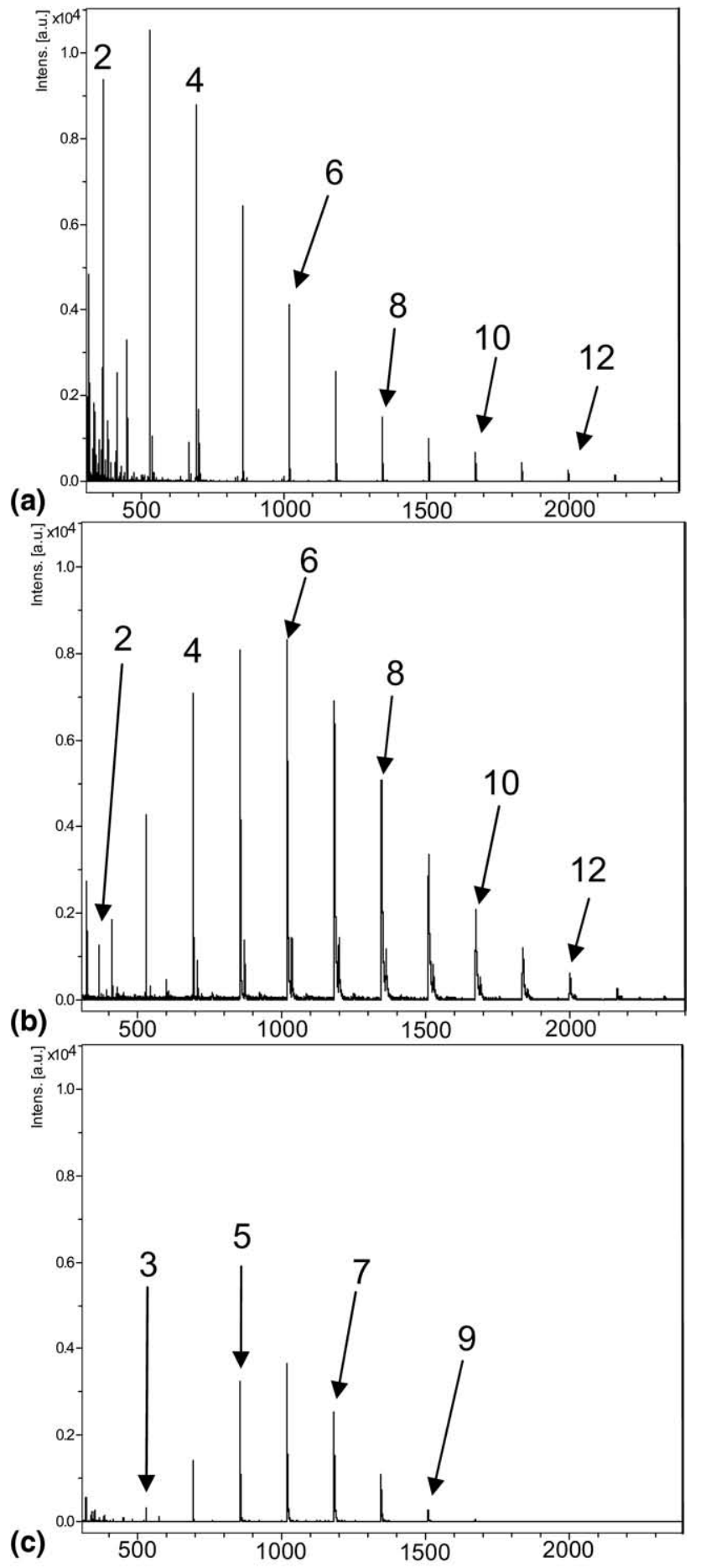

Figure 4. Spectra of dextran enzymatic synth. $\left(\mathrm{M}_{\mathrm{w}}=1500 \mathrm{Da}\right)$ using (a) DHB, (b) DIEA F, and (c) DIEA CHCA. Peak numbers represent the number of sodiated glucose units.

Figure $4 \mathrm{~b}$ shows the spectrum of dextran 1500 using DIEA FA as a matrix. It can be clearly seen that the spectrum obtained with the ILM shows a more uniform, almost Gaussian distribution of peaks representing two to 14 glucose units. Spectrum $4 \mathrm{~B}$ also shows a second smaller distribution of peaks, which represents potassium adducts of the dextran. It has been noticed exper- 
imentally that ferulic ionic liquids tend to promote the formation of sodium and potassium adducts more than CHCA or sinapinic ionic liquids. The $M_{n}$ and $M_{w}$ of the sodium adduct distribution for dextran 1500 is 1208 and $1305 \mathrm{Da}$, respectively. The potassium adduct distribution shows a $\mathrm{M}_{\mathrm{n}}$ of $1274 \mathrm{Da}$ and a $\mathrm{M}_{\mathrm{w}}$ of $1319 \mathrm{Da}$. The discrepancy between the listed $\mathrm{M}_{\mathrm{r}}$ of $1500 \mathrm{Da}$ and the MALDI $M_{w}$ of 1305 is assumed to be due to differences of the SEC standard polymers and the dextran [41, 42]. Figure 4c shows the spectrum of dextran 1500 using DIEA CHCA as a matrix. DIEA CHCA shows a smaller but still uniform distribution of sodium adduct peaks representing three to nine glucose units. The distribution shows a $M_{n}$ of $1063 \mathrm{Da}$ and a $M_{w}$ of $1085 \mathrm{Da}$. The $M_{n}$ and $M_{w}$ of the spectrum obtained with DIEA CHCA (see the Experimental section) is less than that of the spectrum from DIEA $F$ because fewer high mass peaks were detected with DIEA CHCA, making $\mathrm{M}_{\mathrm{n}}$ and $\mathrm{M}_{\mathrm{w}}$ smaller. Although we do not vouch for the accuracy of the Bruker Polytools software program (see Experimental), clearly the IL matrices give a more uniform distribution of molecular weights and higher average molecular weights; most likely leading to more accurate mass determinations.

Figure 5 shows the detection of mannan from Saccharomyces cerevisiae with (a) IMTBA CHCA, (b) DIEA CHCA, and (c) DHB. No molecular weight information could be obtained from the manufacturer of the mannan (see the Experimental section). Figure 5a shows the spectrum of mannan using IMTBA CHCA as a matrix. The spectra of mannan using ionic liquid matrices show a uniform distribution. The peaks in Figure 5a represent the sodium adducts of five to 20 mannose units. The $M_{n}$ and $\mathrm{M}_{\mathrm{w}}$ of the sodium adduct distribution for mannan

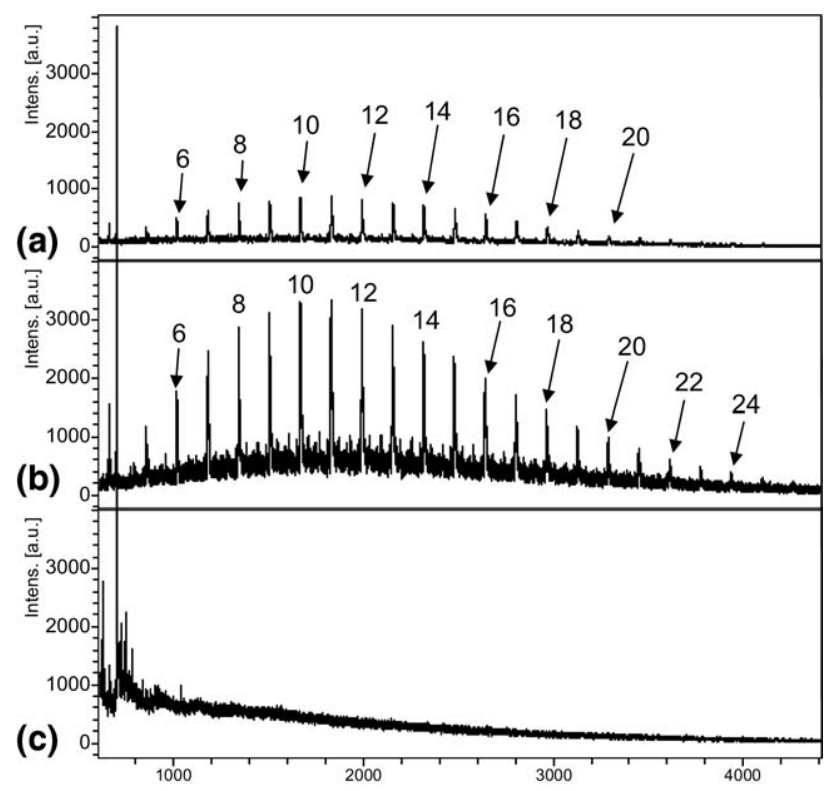

Figure 5. Spectra of mannan from Saccharomyces cerevisiae using (a) IMTBA CHCA, (b) DIEA CHCA, and (c) DHB. Peak numbers represent the number of sodiated mannose units. is 2074 and 2256 Da, respectively. Figure 5b shows the spectrum obtained for mannan with the DIEA CHCA matrix. The peaks represent the sodium adducts of five to 24 mannan units with the $M_{n}$ and $M_{w}$ equal to 2183 and $2431 \mathrm{Da}$, respectively. Figure $5 \mathrm{c}$ shows that when DHB is used as a matrix, no polymer signal can be seen. CHCA was also tested for the detection of mannan with similar results (data not shown).

\section{Conclusions}

The new generation of ILMs have shown themselves to be exceptional MALDI matrices. These ILMs have a practical mass working range from less than $1000 \mathrm{Da}$ to greater than $270,000 \mathrm{Da}$ for peptides and proteins. They also exhibit the ability to detect many different types of analytes. It also can be seen that the ILMs are able to detect noncovalent protein complexes or $n$-mers of proteins.

Analyte signal intensity produced by these ILMs have been shown to be dependent on the $\mathrm{pK}_{\mathrm{a}}$ and proton affinity of the tertiary amine cations used, with the minimum requirements being $\geq 11$ and $\geq 930 \mathrm{~kJ} /$ mol, respectively. It was also shown that these ILMs can be used to detect analytes, such as polysaccharides, with fewer degradation products. It was found that the DIEA CHCA and IMTBA CHCA worked best for proteins and peptides, and that DIEA CHCA and DIEA F worked best for carbohydrates. The search for new anions, cations, and unique analytes is ongoing and will be presented in subsequent publications.

\section{Acknowledgments}

The authors thank the Robert A. Welch foundation (Y-0026) for its support.

\section{Appendix A Supplementary Material}

Supplementary material associated with this article may be found in the online version at doi:10.1016/ j.jasms.2009.05.020.

\section{References}

1. Pino, V.; Anderson, J. L.; Ayala, J. H.; Gonzalez, V.; Afonso, A. M. The Ionic Liquid 1-Hexadecyl-3-Methylimidazolium Bromide as Novel Extracting System for Polycyclic Aromatic Hydrocarbons Contained in Sediments using Focused Microwave-Assisted Extraction. J. Chromatogr. A 2008, 1182, 145-152.

2. Lohithakshan, K. V.; Aggarwal, S. K. Solvent Extraction Studies of $\mathrm{Pu}(\mathrm{IV})$ with CMPO in 1-Octyl 3-Methyl Imidazolium Hexa Fluorophosphate (C8mimPF6) Room Temperature Ionic Liquid (RTIL). Radiochim. Acta 2008, 96, 93-97.

3. Lo, W.; Yang, H.; Wei, G. One-Pot Desulphurization of Light Oils by Chemical Oxidation and Solvent Extraction with Room Temperature Ionic Liquids. Green Chem. 2003, 5, 639-642.

4. Pei, Y.; Wu, K.; Wang, J.; Fan, J. Recovery of Furfural from Aqueous Solution by Ionic Liquid Based Liquid-Liquid Extraction. Sep. Sci. Technol. 2008, 43, 2090-2102.

5. Carda-Broch, S.; Berthod, A.; Armstrong, D. W. Solvent Properties of the 1-Butyl-3-Methylimidazolium Hexafluorophosphate Ionic Liquid. Anal. Bioanal. Chem. 2003, 375, 191-199.

6. Baltazar, Q. Q.; Leininger, S. K.; Anderson, J. L. Binary Ionic Liquid Mixtures as Gas Chromatography Stationary Phases for Improving the 
Separation Selectivity of Alcohols and Aromatic Compounds. J. Chromatogr. A 2008, 1182, 119-127.

7. Huang, K.; Han, X.; Zhang, X.; Armstrong, D. W. PEG-Linked Geminal Dicationic Ionic Liquids as Selective, High-Stability Gas Chromatographic Stationary Phases. Anal. Bioanal. Chem. 2007, 389, 2265-2275.

8. Seeley, J. V.; Seeley, S. K.; Libby, E. K.; Breitbach, Z. S.; Armstrong, D. W. Comprehensive Two-Dimensional Gas Chromatography Using a HighTemperature Phosphonium Ionic Liquid Column. Anal. Bioanal. Chem. 2008, 390, 323-332.

9. Breitbach, Z. S.; Armstrong, D. W. Characterization of Phosphonium Ionic Liquids through a Linear Solvation Energy Relationship and their use as GLC Stationary Phases. Anal. Bioanal. Chem. 2008, 390, 1605-1617.

10. Lambertus, G. R.; Crank, J. A.; McGuigan, M. E.; Kendler, S.; Armstrong, D. W.; Sacks, R. D. Rapid Determination of Complex Mixtures by Dual-Column Gas Chromatography with a Novel Stationary Phase Combination and Spectrometric Detection. J. Chromatogr. A 2006, 1135, 230-240.

11. Anderson, J. L.; Armstrong, D. W. Immobilized Ionic Liquids as High-selectivity/high-temperature/high-Stability Gas Chromatography Stationary Phases. Anal. Chem. 2005, 77, 6453-6462.

12. Ding, J.; Welton, T.; Armstrong, D. W. Chiral Ionic Liquids as Stationary Phases in Gas Chromatography. Anal. Chem. 2004, 76, 6819-6822.

13. Carda-Broch, S.; Berthod, A.; Armstrong, D. W. Ionic Matrices for Matrix-Assisted Laser desorption/ionization Time-of-Flight Detection of DNA Oligomers. Rapid Commun. Mass Spectrom. 2003, 17, 553-560.

14. Armstrong, D. W.; Zhang, L.; He, L.; Gross, M. L. Ionic Liquids as Matrixes for Matrix-Assisted Laser desorption/ionization Mass Spectrometry. Anal. Chem. 2001, 73, 3679-3686.

15. Li, Y. L.; Gross, M. L. Ionic-Liquid Matrices for Quantitative Analysis by MALDI-TOF Mass Spectrometry. J. Am. Soc. Mass Spectrom. 2004, 15, 1833-1837.

16. Zabet-Moghaddam, M.; Krueger, R.; Heinzle, E.; Tholey, A. MatrixAssisted Laser desorption/ionization Mass Spectrometry for the Characterization of Ionic Liquids and the Analysis of Amino Acids, Peptides, and Proteins in Ionic Liquids. J. Mass Spectrom. 2004, 39, 1494-1505.

17. Li, Y. L.; Gross, M. L.; Hsu, F. Ionic-Liquid Matrices for Improved Analysis of Phospholipids by MALDI-TOF Mass Spectrometry. J. Am. Soc. Mass Spectrom. 2005, 16, 679-682.

18. Ramos, C. R.; de Azevedo, M. L.; Silva, S. L.; Baptista, A. S.; Gloria, E. M.; Calori-Domingues, M. A.; Facco Elizete, M. P.; Eberlin, M. N. Aflatoxin Screening by MALDI-TOF Mass Spectrometry. Anal. Chem. 2005, 77, 8155-8157.

19. Santos, L. S.; Haddad, R.; Hoeehr, N. F.; Pilli, R. A.; Eberlin, M. N. Fast Screening of Low Molecular Weight Compounds by Thin-Layer Chromatography and "on-Spot" MALDI-TOF Mass Spectrometry. Anal. Chem. 2004, 76, 2144-2147.

20. Soukup-Hein, R. J.; Remsburg, J. W.; Dasgupta, P. K.; Armstrong, D. W A General, Positive Ion Mode ESI-MS Approach for the Analysis of Singly Charged Inorganic and Organic Anions using a Dicationic Reagent. Anal. Chem. 2007, 79, 7346-7352.

21. Remsburg, J. W.; Soukup-Hein, R. J.; Crank, J. A.; Breitbach, Z. S.; Payagala, T.; Armstrong, D. W. Evaluation of Dicationic Reagents for their use in Detection of Anions using Positive Ion Mode ESI-MS Via Gas Phase Ion Association. J. Am. Soc. Mass Spectrom. 2008, 19, 261-269.

22. Soukup-Hein, R. J.; Remsburg, J. W.; Breitbach, Z. S.; Sharma, P. S.; Payagala, T.; Wanigasekara, E.; Huang, J.; Armstrong, D. W. Evaluating the use of Tricationic Reagents for the Detection of Doubly Charged Anions in the Positive Mode by ESI-MS. Anal. Chem. 2008, 80, 26122616.

23. Downard, K. M. Mass Spectrometry of Protein Interaction, Chap. 2; John W. Wiley \& Sons: Hoboken, 2007; pp 25-43.
24. Tholey, A.; Zabet-Moghaddam, M.; Heinzle, E. Quantification of Peptides for the Monitoring of Protease-Catalyzed Reactions by MatrixAssisted Laser Desorption/Ionization Mass Spectrometry using Ionic Liquid Matrixes. Anal. Chem. 2006, 78, 291-297.

25. Laremore, T. N.; Zhang, F.; Linhardt, R. J. Ionic Liquid Matrix for Direct UV-MALDI-TOF-MS Analysis of Dermatan Sulfate and Chondroitin Sulfate Oligosaccharides. Anal. Chem. 2007, 79, 1604-1610.

26. Lemaire, R.; Tabet, J. C.; Ducoroy, P.; Hendra, J. B.; Salzet, M.; Fournier, I. Solid Ionic Matrixes for Direct Tissue Analysis and MALDI Imaging. Anal. Chem. 2006, 78, 809-819.

27. Tholey, A.; Heinzle, E. Ionic (Liquid) Matrices for Matrix-Assisted Laser desorption/ionization Mass Spectrometry-Applications and Perspectives. Anal. Bioanal. Chem. 2006, 386, 24-37.

28. Naumann, I.; Darsow, K. H.; Walter, C.; Lange, H. A.; Buchholz, R. Identification of Sulfoglycolipids from the Alga Porphyridium purpureum by Matrix-Assisted Laser Desorption/Ionization Quadrupole Ion Trap Time-of-Flight Mass Spectrometry. Rapid Commun. Mass Spectrom. 2007, $21,3185-3192$.

29. Fukuyama, Y.; Nakaya, S.; Yamazaki, Y.; Tanaka, K. Ionic Liquid Matrixes Optimized for MALDI-MS of Sulfated/Sialylated/Neutral Oligosaccharides and Glycopeptides. Anal. Chem. 2008, 80, 2171-2179.

30. Zehl, M.; Allmaier, G. Instrumental Parameters in the MALDI-TOF Mass Spectrometric Analysis of Quaternary Protein Structures. Anal. Chem. 2005, 77, 103-110.

31. Cohen, L. R. H.; Strupat, K.; Hillenkamp, F. Analysis of Quaternary Protein Ensembles by Matrix Assisted Laser desorption/ionization Mass Spectrometry. J. Am. Soc. Mass Spectrom. 1997, 8, 1046-1052.

32. Moniatte, M.; Lesieur, C.; Vecsey-Semjen, B.; Buckley, J. T.; Pattus, F.; van der Goot, F. G.; Van Dorsselaer, A. Matrix-Assisted Laser Desorption-Ionization Time-of-Flight Mass Spectrometry in the Subunit Stoichiometry Study of High-Mass Noncovalent Complexes. Int. J. Mass Spectrom. Ion Processes 1997, 169/170, 179-199.

33. Bhowmick, R.; Jagannadham, M. V. Multiple Intermediate Conformations of Jack Bean Urease at Low pH: Anion-Induced Refolding. Protein J. 2006, 25, 399-410.

34. Guo, Z.; He, L. A Binary Matrix for Background Suppression in MALDI-MS of Small Molecules. Anal. Bioanal. Chem. 2007, 387, 19391944.

35. Mirza, S. P.; Raju, N. P.; Vairamani, M. Estimation of the Proton Affinity Values of Fifteen Matrix-Assisted Laser Desorption/Ionization Matrices Under Electrospray Ionization Conditions Using the Kinetic Method. J. Am. Soc. Mass Spectrom. 2004, 15, 431-435.

36. Beltran, J. L.; Sanli, N.; Fonrodona, G.; Barron, D.; Ozkan, G.; Barbosa, J. Spectrophotometric, Potentiometric and Chromatographic pKa Values of Polyphenolic Acids in Water and Acetonitrile-Water Media. Anal. Chim. Acta 2003, 484, 253-264.

37. Burton, R. D.; Watson, C. H.; Eyler, J. R.; Lang, G. L.; Powell, D. H. Avery, M. Y. Proton Affinities of Eight Matrixes used for MatrixAssisted Laser Desorption/Ionization. Rapid Commun. Mass Spectrom. 1997, 11, 443-446.

38. Hunter, E. P. L.; Lias, S. G. Evaluated Gas Phase Basicities and Proton Affinities of Molecules: An Update. J. Phys. Chem. Ref. Data 1998, 27, 413-656.

39. da Silva, E. F.; Svendsen, H. F. Prediction of the pKa Values of Amines Using $\mathrm{Ab}$ Initio Methods and Free-Energy Perturbations. Ind Eng Chem Res. 2003, 42, 4414-4421.

40. Simekova, M.; Berek, D. Studies on High-Performance Size-Exclusion Chromatography of Synthetic Polymers. J. Chromatogr. A 2005, 1084, 167-172.

41. Netopilik, M.; Kratochvil, P. Polystyrene-Equivalent Molecular Weight Versus True Molecular Weight in Size-Exclusion Chromatography. Polymer 2003, 44, 3431-3436. 